\title{
Проект нового кодекса РФ об административных правонарушениях Кто виноват и что делать?
}

И. В. Болдырев

удК 342.9

\begin{abstract}
Обсуждается опубликованный на сайте https://regulation.gov.ru/ проект нового Кодекса рФ об административных правонарушениях, подготовленный Министерством юстиции РФ. Подробно рассмотрены пункты Главы 24, в которой собраны «административные правонарушения в области технического регулирования, обеспечения единства измерений, геодезии и картографии, а также в области аккредитации в национальной системе аккредитации". Отмечено несоответствие ряда положений проекта Кодекса действующему Закону «О техническом регулировании» и его расширительное толкование. Некоторые статьи идут вразрез с Договором о Евразийском экономическом союзе и другими официальными документами, есть пункты, которые дублируют статьи УК РФ, давая нарушителям возможность уйти от уголовной ответственности. Предложено изменить некоторые формулировки КоАП РФ, а ряд пунктов, по мнению автора, следует исключить.
\end{abstract}

ключевые слова: административный кодекс, аккредитация, техническое регулирование, испытательные лаборатории

A draft of the new Code of Administrative Offenses of the Russian Federation, prepared by the Ministry of Justice of the Russian Federation published on the website https://regulation.gov.ru/ is discussed. The items of Chapter 24 are examined in detail, which contains"administrative offenses in the field of technical regulation, ensuring the uniformity of measurements, geodesy and cartography, as well as in the field of accreditation in the national accreditation system". The inconsistency of a number of provisions of the draft Code with the current Law On Technical Regulation and its broad interpretation were noted. Some articles are contrary to the Treaty on the Eurasian Economic Union and other official documents, there are paragraphs that duplicate the articles of the Criminal Code, giving violators the opportunity to evade criminal liability. Changes to some formulations of the CAO RF are proposed, and a number of points, according to the author, should be deleted.

Keywords: administrative code, accreditation, technical regulation, testing laboratories

Статья получена 02.03.2020 Принята к публикации 12.05.2020

Постановка вопросов, вынесенных в заголовок статьи, является для России традиционной. При возникновении любых проблем начинается поиск виноватых, который заканчивается, как гласит народная мудрость, наказанием невиновных.

1 ААЦ "Аналитика", Москва, boldyrev@aac-analitica.ru.
Из первых пяти статей Главы 24 проекта АК следует, что Минюст видит большие риски, связанные с тем, что производители выпускают недоброкачественную продукцию и пытаются выдавать ее за доброкачественную, обманывая тем самым покупателя и нанося ему ущерб. Понятно, что государство должно заступаться за своих граждан, потому 
как гражданину трудно (хотя и возможно) защитить свои права в споре с юридическими лицами.

Менее понятна позиция Минюста в отношении испытательных лабораторий. Как правило, испытательные лаборатории напрямую с гражданами не взаимодействуют. Чей же тогда интерес призвана защищать установленная в ст. 24.6 ответственность испытательных лабораторий? Интерес их заказчиков - органов по сертификации и производителей продукции? Трудно представить ситуацию, в которой испытательная лаборатория была бы заинтересована обмануть своего заказчика. Скорее, угроза беспристрастности исходит от самих заказчиков, которые действительно не хотят получать от лабораторий протоколы испытаний, свидетельствующие о недостатках их продукции. Но, возможно, Минюсту, Минпромторгу, Росаккредитации, Росстандарту известно больше, чем нам, и они понимают, зачем надо "затягивать гайки". Что же может нарушить испытательная лаборатория и что можно изменить в предлагаемых формулировках?

Рассмотрим и обсудим содержание ряда статей подробнее.

\section{Статья 24.6. Представление недостовер- ных результатов исследований (испытаний) и измерений для целей оценки (подтвержде- ния) соответствия продукции}

Закон о техническом регулировании устанавливает требование об обеспечении достоверности результатов исследований (испытаний) и измерений только применительно к обязательной сертификации. Понятие "для целей оценки (подтверждения) соответствия" значительно шире обязательной сертификации. Таким образом, настоящая статья устанавливает административную ответственность практически для всех лабораторий, так как оценка соответствия - это задача более чем 90\% всех испытаний в нашей стране.

С целью приведения ст. 26.4 Кодекса в соответствие с Законом "О техническом регулировании" (ст. 26) предлагается в заголовке статьи заменить слова "оценки (подтверждения) соответствия" на слова "обязательной сертификации" и утвердить ее в следующей формулировке: Представление недостоверных результатов исследований (испытаний) и измерений для целей обязательной сертификации.

Поскольку понятие "недостоверный результат" не определено, предлагаем дать примечание к ст. 24.6 в следующей формулировке:
Под недостоверными результатами исследований (испытаний) и измерений понимаются результаты исследований (испытаний) и измерений, несовместимые со значением определяемой характеристики, которая стала известна в ходе арбитражного исследования (испытаний) и измерений или с теоретическими или практическими границами значений этой характеристики.

В частности, следует признать недостоверным результат измерения рН воды, равный 16.

\section{Статья 24.6. Часть 1}

Выдача испытательной лабораторией для целей оценки (подтверждения) соответствия продукции, протокола исследований и (испытаний) и (или) измерений и иного документа без проведения исследований (испытаний) и (или) измерений.

Включение в AK этой статьи поможет преступникам избежать уголовного преследования, поскольку УК содержит ст. 292, которая рассматривает служебный подлог (то есть внесение должностным лицом, а также государственным служащим или муниципальным служащим, не являющимся должностным лицом, в официальные документы заведомо ложных сведений, а равно внесение в указанные документы исправлений, искажающих их действительное содержание) как уголовное преступление.

Предлагается ст. 24.6 часть 1 исключить.

\section{Статья 24.6. Часть 2}

Выдача испытательной лабораторией (центром) для целей оценки (подтверждения) соответствия продукции протокола исследований (испытаний) и измерений или иного документа с нарушением требований законодательства о техническом регулировании, правил и методов исследований (испытаний) и измерений, содержащих недостоверные или необъективные результаты исследований (испытаний) и измерений.

Закон о техническом регулировании устанавливает для испытательных лабораторий только требование "обеспечить достоверность результатов исследований (испытаний) и измерений" (ст. 26 ч. 4) и не предусматривает выдачи испытательными лабораториями никаких иных документов, кроме протокола испытаний. 
Закон о техническом регулировании устанавливает требование об обеспечении достоверности результатов исследований (испытаний) и измерений только применительно к обязательной сертификации.

Вопрос объективности результатов исследований (испытаний) и измерений явно подчинен достоверности. Если результат достоверен, то не имеет значения его объективность.

Предлагается ст. 24.6.2 АК изложить в следующей редакции: Выдача испытательной лабораторией (центром) для целей обязательной сертификации продукции протокола исследований (испытаний) и измерений, содержащих недостоверные результаты исследований (испытаний) и измерений.

\section{Статья 24.6. Часть 3}

Неприменение изготовителем продукции (лицом, выполняющим функции иностранного изготовителя), исполнителем работ (услуг) национального стандарта Российской Федерации в случае публичного заявления о соответствии выпускаемой продукции, оказываемых услуг, выполняемых работ такому национальному стандарту, в том числе в случае применения обозначения такого национального стандарта в маркировке, в эксплуатационной или иной документации, и (или) при маркировке продукции знаком национальной системы стандартизации.

Предлагается исключить (перенести в другую статью), так как содержание правонарушения не относится к деятельности, связанной с исследованиями, испытаниями и измерениями.

\section{Статья 24.14. Нарушение законодательства об обеспечении единства измерений Часть 1}

Нарушение законодательства об обеспечении единства измерений в части выполнения измерений, относящихся к сфере государственного регулирования обеспечения единства измерений, без применения аттестованных методик (методов) измерений, с несоблюдением требований аттестованных методик (методов) измерений, несоблюдение обязательных требований к измерениям (в том числе отсутствие необходимых средств измерений), либо несоблюдения установленного порядка уведомления о своейдеятельности по выпуску из производства предназначенных для применения в сфере государственного регулирования обеспечения единства измерений эталонов единиц величин, стандартных образцов и (или) средств измерений или по их ввозу на территорию Российской Федерации и продаже, либо несоблюдения порядка проведения испытаний стандартных образцов или средств измерений в целях утверждения типа, порядка поверки средств измерений, либо применения в сфере государственного регулирования обеспечения единства измерений стандартных образцов неутвержденного типа, средств измерений неутвержденного типа и (или) не прошедших в установленном порядке поверку, либо несоблюдения обязательных метрологических и технических требований к средствам измерений и обязательных требований к условиям их эксплуатации, либо несоблюдения порядка утверждения, содержания, сличения и применения государственных первичных эталонов единиц величин, порядка передачи единиц величин от государственных эталонов, порядка установления обязательных требований к эталонам единиц величин, используемым для обеспечения единства измерений в сфере государственного регулирования обеспечения единства измерений, порядка оценки соответствия этим требованиям и порядка их применения, либо использования в сфере государственного регулирования обеспечения единства измерений, не допущенных к применению в Российской Федерации единиц величин, за исключением случаев, предусмотренных частями 2 и 3 настоящей статьи.

1. Предлагается исключить слова несоблюдения порядка проведения испытаний стандартных образцов или средств измерений в целях утверждения типа. Поскольку государственное регулирование осуществляется в форме включения средств измерений и стандартных образцов в соответствующий Федеральный реестр, то в случае выявления нарушений Росстандарт не будет их вносить.

2. Предлагается исключить слова по их ввозу на территорию Российской Федерации. Стандартные образцы и средства измерений применяются не только в области государственного регулирования. Если вообще запретить их ввоз на территорию РФ, то хозяйствующие субъекты не смогут их применять в добровольной сфере. На этапе ввоза невозможно обоснованно решить, для каких целей 
ввозится стандартный образец, средство измерений или эталон.

3. Стандартные образцы зарубежных производителей широко применяются в России. Это связано с недостаточной обеспеченностью стандартными образцами российского производства. При этом зарубежные производители далеко не горят желанием вносить свои стандартные образцы в российский реестр. Отказ от применения иностранных СО (пестицидов, стеринов, антибиотиков, действующих веществ лекарственных препаратов и т. п.) сделает невозможными испытания и измерения широкого спектра продукции. Предлагается исключить слова либо применения в сфере государственного регулирования обеспечения единства измерений стандартных образцов неутвержденного типа.

4. Словосочетание "требований аттестованных методик (методов) измерений" создает возможность для широкой трактовки нарушения, так как в документах, регламентирующих методики (методы) измерений, положения, относящиеся к требованиям, как правило, не выделяются. В ряде случаев пользователи методик вынуждены идти на разумные отклонения от указаний в методиках, например, когда применяют оборудование с лучшими характеристиками. Предлагается в П. 24.14 заменить слова "с несоблюдением требований аттестованных методик (методов) измерений" на: с несоблюдением требований аттестованных методик (методов) измерений, приводящим к ухудшению показателей точности результатов измерений.

\section{Статья 24.15. Нарушение порядка распростра- нения документов по стандартизации \\ Нарушение установленного порядка распростра- нения документов национальной системы стан- дартизации, общероссийских классификаторов технико-экономической и социальной информа- ции, сводов правил, международных стандартов, региональных стандартов и региональных сво- дов правил, стандартов иностранных государств и сводов правил иностранных государств, иных документов по стандартизации иностранных государств, документов международных органи- заций по стандартизации и региональных орга- низаций по стандартизации.}

Распространение стандартов является обязанностью Федерального органа в сфере стандартизации. Закон о стандартизации в ст. 40 устанавливает обязанность официального опубликования стандартов, но вовсе не запрещает иным лицам заниматься распространением документов. Во всяком случае не понятно, что плохого в том, чтобы распространение стандартов шло более интенсивно.

Во всяком случае Закон о стандартизации в своей первой статье устанавливает, что он "не распространяется на стандарты, которые не относятся к документам по стандартизации, предусмотренным ст. 14 настоящего Федерального закона". В ст. 14 к таким документам не отнесены международные стандарты, региональные стандарты и региональные своды правил, стандарты иностранных государств и своды правил иностранных государств, иные документы по стандартизации иностранных государств, документы международных организаций по стандартизации и региональных организаций по стандартизации. Предлагается этот перечень исключить из текста проекта АК.

Кроме того, неплохо было бы установить ответственность за распространение стандартов в искаженном виде, именно с этим все чаще приходится сталкиваться.

Статья 24.21. Нарушение юридическим лицом, индивидуальным предпринимателем требований законодательства Российской Федерации об аккредитации в национальной системе аккредитации

Часть 1

Проведение аккредитованным в национальной системе аккредитации лицом работ (оказание услуг) по оценке соответствия, в том числе по приему и рассмотрению документов, необходимых для проведения указанных работ (оказания услуг), в целях выдачи сертификата соответствия, протокола исследований (испытаний) и (или) измерений и иных документов, не по месту осуществления деятельности данного лица, указанному в реестре аккредитованных лиц, за исключением проведения работ (оказания услуг) по месту осуществления временных работ в случаях и в порядке, предусмотренном законодательством Российской Федерации об аккредитации в национальной системе аккредитации.

Выявление фактов работы испытательных лабораторий по адресам, не указанным в реестре, приводит в приостановке или прекращению аккредитации, что уже является серьезным наказанием. Для испытательной лаборатории дополнительный административный штраф представляется совершенно избыточным и несоразмерным вине. 


\section{Статья 24.21. Часть 2}

Выдача органом по сертификации сертификата соответствия на основании протокола исследований (испытаний) и (или) измерений или иных документов, содержащих сведения об исследованиях (испытаниях) и (или) измерениях, выданных лицами, аккредитация которых в национальной системе аккредитации на момент выдачи сертификата соответствия прекращена, либо область аккредитации которых на проведение соответствующих работ на момент выдачи сертификата соответствия сокращена в соответствии с законодательством Российской Федерации об аккредитации в национальной системе аккредитации, а равно срок действия документа об аккредитации которых на момент выдачи сертификата соответствия истек.

В соответствии с Договором о Евразийском экономическом союзе (Приложение № 9 «Протокол о техническом регулировании в рамках Евразийского экономического союза") допускается использование протоколов испытаний лабораторий, аккредитованных не только в Российской национальной системе аккредитации.

Предлагается изложить в редакции: Выдача органом по сертификации сертификата соответствия на основании протокола исследований (испытаний) и (или) измерений или иных документов, содержащих сведения об исследованиях (испытаниях) и (или) измерениях, выданных лицами, аккредитация которых на момент выдачи сертификата соответствия прекращена, либо область аккредитации которых на проведение соответствующих работ на момент выдачи сертификата соответствия сокращена, а равно срок действия документа об аккредитации которых на момент выдачи сертификата соответствия истек.

\section{Статья 24.21. Часть 3}

Выдача аккредитованным в национальной системе аккредитации лицом сертификата соответствия, протокола исследований (испытаний) и (или) измерений, иных документов со ссылкой на аккредитацию в национальной системе аккредитации в случае приостановления аккредитации или в случае, если выдача указанных документов не предусмотрена областью аккредитации аккредитованного лица.
Содержание этой части статьи не охватывает случаев, когда аккредитация выдана не в национальной системе аккредитации, а, например, в органе по аккредитации страны-участника Евразийского экономического союза.

Предлагается изложить в редакции: Выдача аккредитованным лицом сертификата соответствия, протокола исследований (испытаний) и (или) измерений, иных документов со ссылкой на аккредитацию в случае приостановления аккредитации или в случае, если выдача указанных документов не предусмотрена областью аккредитации аккредитованного лица.

\section{Статья 24.21. Часть 4}

Выдача юридическим лицом, индивидуальным предпринимателем, не имеющим аккредитации в национальной системе аккредитации, сертификата соответствия, протокола исследований (испытаний) и (или) измерений, иных документов со ссылкой на аккредитацию в национальной системе аккредитации, либо в случае, когда в соответствии с положениями федеральных законов получение такой аккредитации является обязательным.

Закон "Об аккредитации в национальной системе аккредитации" не устанавливает обязательности аккредитации испытательных лабораторий. В статье АК "Нарушение юридическим лицом, индивидуальным предпринимателем требований законодательства Российской Федерации об аккредитации в национальной системе аккредитации" не может устанавливаться ответственность за нарушение иных законов.

Предлагается изложить в следующей редакции: Выдача юридическим лицом, индивидуальным предпринимателем, не имеющим аккредитации в национальной системе аккредитации, сертификата соответствия, протокола исследований (испытаний) и (или) измерений, иных документов со ссылкой на аккредитацию в национальной системе аккредитации.

\section{Статья 24.21. Часть 5}

Выдача испытательной лабораторией протокола исследований (испытаний) и (или) измерений или иного документа без проведения исследований (испытаний) и (или) измерений в случаях, 
когда в соответствии с федеральными законами аккредитация на проведение соответствующих исследований (испытаний) и (или) измерений является обязательной, за исключением административных правонарушений, предусмотренных статьей 24.6 настоящего Кодекса.

УК содержит ст. 292, которая рассматривает подлог как уголовное преступление. Состав преступления, описанный в этой статье, полностью охватывает описанное в проекте АК ст. 24.21 ч. 5 правонарушение. Включение в АК этой статьи позволит преступникам избегать уголовного преследования.

Кроме того, закон "Об аккредитации в национальной системе аккредитации" не устанавливает обязательности аккредитации. В статье АК "Нарушение юридическим лицом, индивидуальным предпринимателем требований законодательства Российской Федерации об аккредитации в национальной системе аккредитации" не может устанавливаться ответственность за нарушение иных законов.

Предлагается ч. 5 ст. 24.21 исключить.

\section{Статья 24.21. Часть 6 \\ Выдача испытательной лабораторией (центром) протокола исследований (испытаний) и (или) измерений или иного документа с нарушением правил и методов исследований (испытаний) и (или) измерений, которое повлекло недосто- верные или необъективные результаты исследо- ваний (испытаний) и (или) измерений, в случаях, когда в соответствии с федеральными законами аккредитация на проведение соответствующих исследований (испытаний) и (или) измерений является обязательной, за исключением админи- стративных правонарушений, предусмотренных статьей 24.6 настоящего Кодекса.}

Закон «Об аккредитации в национальной системе аккредитации" не устанавливает обязательности аккредитации. В статье АК "Нарушение юридическим лицом, индивидуальным предпринимателем требований законодательства Российской Федерации об аккредитации в национальной системе аккредитации" не может устанавливаться ответственность за нарушение иных законов.

Предлагается ч. 6 ст. 24.21 исключить.

\section{TATAPСТАНСКИЙ THO НЕФТЕГАЗОХИМИЧЕСКИЙ

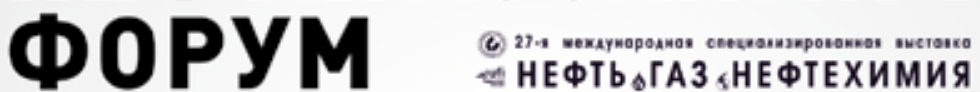

\section{2-4}

ОРГАНИЗАТОРЫ:

Кабинет Министров Республики Татарстан, Министерство промышленности и торговли Республики Татарстан, Мэрия города Казани, OAO «Казанская ярмарка»

ПРИ ПОДДЕРЖКЕ:

Президента Республики Татарстан

МЕСТО ПРОВЕДЕНИЯ:

МВЦ «Казань ЭКспом

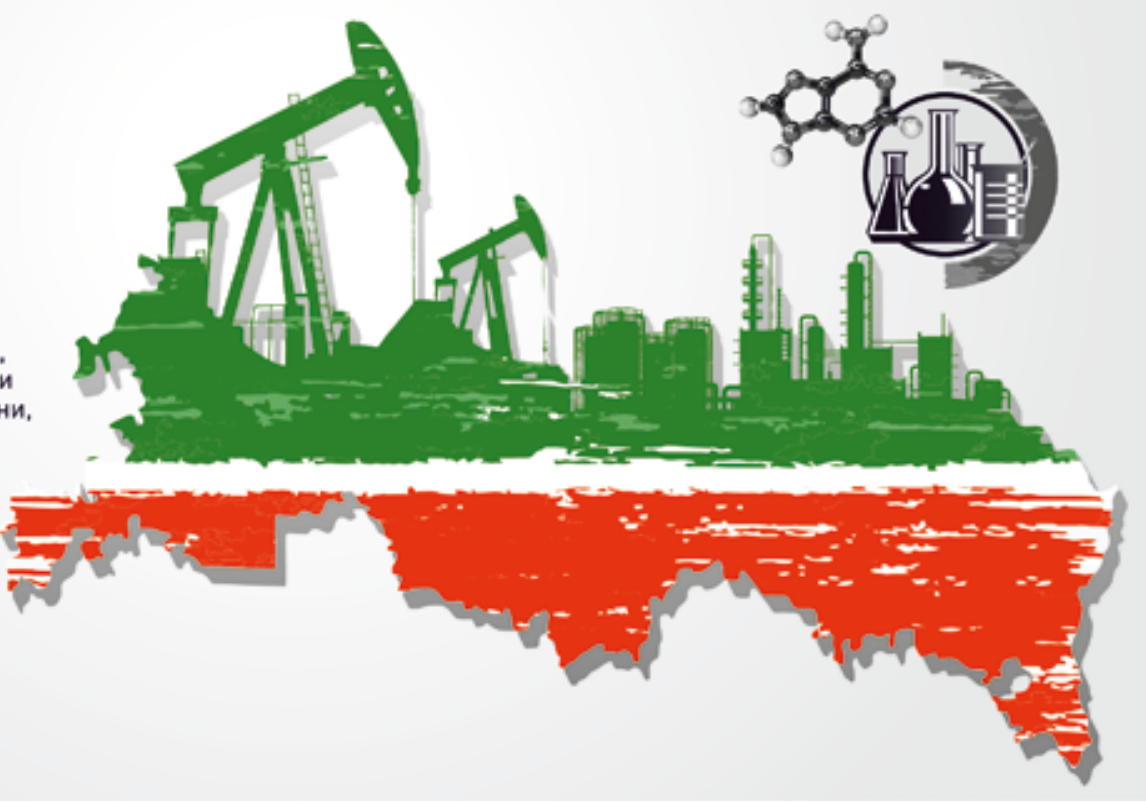




\section{Статья 24.21. Часть 7}

Распространение информации, в том числе посредством информационнотелекоммуникационной сети "Интернет", о работах (услугах) по проведению обязательного подтверждения соответствия, исследований (испытаний) и (или) измерений, необходимых для обязательного подтверждения соответствия, в целях продвижения и реализации работ (услуг) на рынке, в том числе по приему и рассмотрению документов, необходимых для проведения указанных работ (оказания услуг), в случае, если лица, распространяющие данную информацию, не имеют аккредитации в национальной системе аккредитации либо являются аккредитованными в национальной системе аккредитации лицами, но распространяют данную информацию без указания наименования аккредитованного юридического лица (фамилии, имени и (в случае, если имеется) отчества аккредитованного индивидуального предпринимателя) и номера записи в реестре аккредитованных лиц (номера аттестата аккредитации).

Требование избыточно, так как охватывает декларирование соответствия, для которого подобная ответственность не актуальна, так как для этого аккредитация не является обязательной. Предлагается заменить слова "обязательного подтверждения соответствия" на слова "обязательной сертификации".

В соответствии с Договором о Евразийском экономическом союзе (Приложение № 9 «Протокол о техническом регулировании в рамках Евразийского экономического союза") допускается использование протоколов испытаний лабораторий, аккредитованных не только в Российской национальной системе аккредитации.

Предлагается ст. 24.21 ч. 7 изложить в следующей редакции:

Распространение информации, в том числе посредством информационнотелекоммуникационной сети "Интернет", о работах (услугах) по проведению обязательной сертификации, исследований (испытаний) и (или) измерений, необходимых для обязательной сертификации, в целях продвижения и реализации работ (услуг) на рынке, в том числе по приему и рассмотрению документов, необходимых для проведения указанных работ (оказания услуг), в случае, если лица, распространяющие данную информацию, не имеют аккредитации, либо являютя аккредитованными лицами, но распространяют данную информацию без указания наименования аккредитованного юридического лица (фамилии, имени и (в случае, если имеется) отчества аккредитованного индивидуального предпринимателя) и номера записи в реестре аккредитованных лиц (номера аттестата аккредитации).

Итак, после рассмотрения Главы 24 проекта Кодекса об административных правонарушениях подведем некоторые итоги.

1. Административная ответственность испытательных лабораторий продолжает усиливаться.

2. Обоснованность такого усиления представляется сомнительной, вытекающей из ложных посылок: использование неправильной терминологии, игнорирование документов Евразийского экономического союза, расширительное толкование законодательных норм и т. п.

3. Установление административной ответственности в области аккредитации представляется нарушением принципа недопустимости двойного наказания за одно и то же правонарушение. Лишение аккредитации уже само по себе является серьезным наказанием и дополнительно к этому накладывать на испытательную лабораторию административный штраф это избыточная мера.

4. Если ситуация не изменится, то через некоторое время начнется отток сотрудников лабораторий в иные сферы деятельности. Если гайку затягивать слишком сильно, то резьба может сорваться!

Повысят ли предлагаемые административные рычаги, приложенные к испытательным лабораториям, достоверность результатов оценки соответствия? Весьма сомнительно. По мнению специалистов, проблемы достоверности оценки соответствия сегодня лежат в области правильного использования результатов испытаний. Однако при принятии решений о соответствии практически не используется информация о неопределенности результатов измерений и вероятности ложноположительных и ложноотрицательных результатов. Но это уже тема другой статьи. 


\section{КОМПОЗИТ-ЭКСПО}

Тринадцатая международная специализированная выставка

\section{8 - 10 сентября 2020}

Москва, ЦВК «Экепоценіро, наю. 3

\section{Основные разделы выставки:}

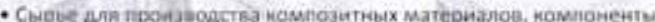

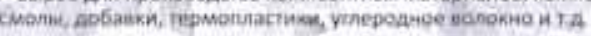

- Hanontestefor in модафикаторы

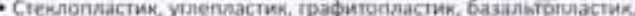

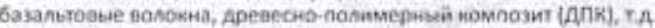

- Полуфабрікіаты (препрети

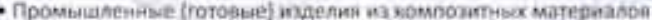

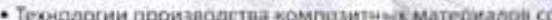

специальнеми и заданінем ми саойстиами

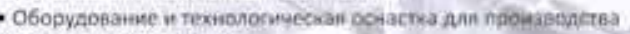

omnsiurtibix Matepuanos

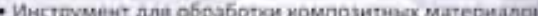





- Konntopteghoе морелирование

- Yromazarari

(1) КЛЕИИ ГЕРМЕТИКИ

Информационная поддержка:

MonR
Дирекция:

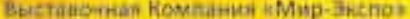

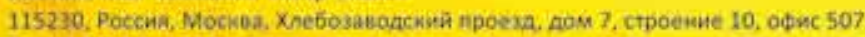

Teh:-8 495 988-1620 I E-mat: infoel composite-expo.ru | Cañ www.composite-expo-ru

You Tube youtube.com/user/compoexporussia 17 igcompoexporus


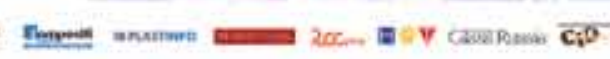


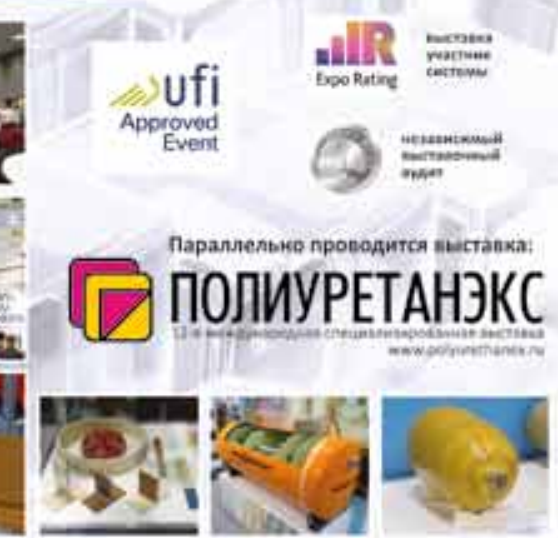

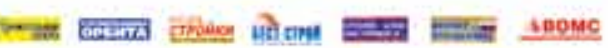



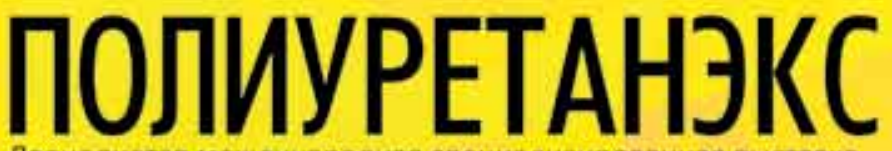

Двенадцатая международная специализированная выставка
Организатор:

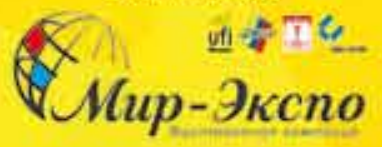

\section{Основные разделы выставки:}

- Сырье длг производства полиуретанов

(добавки, нрасители, катализаторы, наполнители, ит.д.)

- Оборудование и станни дла произоодства и перера6опки полиүретанов

(расходометрия, шестереночние, оседиатональныс (циековые),

шлепперные насосиые установки, обрабатываюице станки, и т.,.)

- Конечкая продухция

(контантное уплотнение при литье, фильтры ит.д.)

- уелуги

( (лабораторные испьтания, охрана здоровьн и безопастность,

переработка, зацита окружаюнцей среды, научные разработки)

- Техническое обслуживание оборудованин

- Tecroude o6 борудование

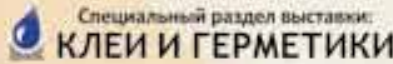

Информационная поддержка:

QQBQ 2 PLASTINFO

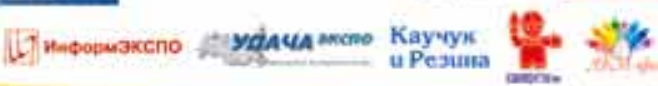
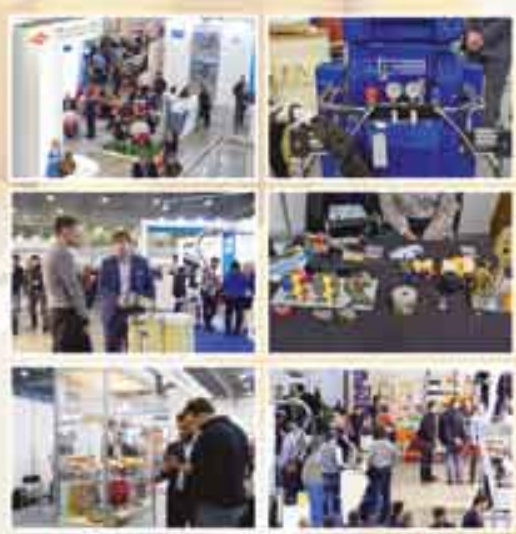

Approved

Elllilir

8 - 10 сентября 2020

Москва, ЦвК «Экспоцентр», лав. 3
Дирекция:

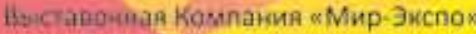

11527 раст, Москва, Хлебозаводский проезд, дом 7, строение 10, офис 507

1620 | E-mall: info@polyurethanex.ru | Сайт: www.polyurethanex.ru

You Tolse
Организатор:

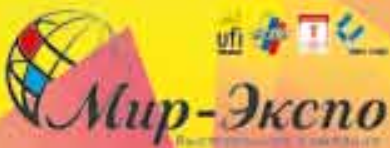

